\title{
Volatile species release during torrefaction of biomass and its macromolecular constituents: Part 2 - Modeling study
}

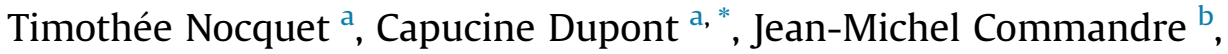 \\ Maguelone Grateau ${ }^{a}$, Sébastien Thiery ${ }^{a}$, Sylvain Salvador ${ }^{\mathrm{c}}$ \\ a CEA Grenoble - LITEN - Laboratory of Technology of Biomass, 17 rue des Martyrs, 38054 Grenoble Cedex 9, France

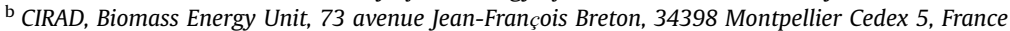 \\ ${ }^{\mathrm{c}}$ MINES ALBI, RAPSODEE, FRE CNRS 3213, France
}

Keywords:
Biomass
Cellulose
Hemicelluloses
Lignin
Model
Torrefaction

\section{Introduction}

The general context of the study is detailed in part 1 of this twopaper series. The reader is invited to consult the experimental part (part 1) before considering the following modeling part (part 2) to better understand the study.

As mentioned in part 1 , at the moment, torrefaction mechanisms are still poorly understood [1]. There are only few kinetic models dedicated to biomass torrefaction [2-4]. These models are mainly inspired from pyrolysis models, for which an abundant literature is available, as reviewed by Di Blasi [5]. Pyrolysis and torrefaction models both describe biomass thermal degradation, but in different ranges of temperature, i.e. the range of temperature in pyrolysis is higher than that associated to torrefaction - typically higher than $300{ }^{\circ} \mathrm{C}$. Hence, the reactions and mechanisms involved are expected to be - at least partly - different and the substantial work done to develop pyrolysis models cannot be directly applied to torrefaction conditions.

\footnotetext{
* Corresponding author

E-mail address: capucine_dupont@hotmail.fr (C. Dupont).
}

As solid is the main product of torrefaction, the objective of torrefaction models is generally the description of solid mass loss versus time and temperature. Only Bates and Ghoniem have recently developed a model able to predict the composition of volatiles [3]. As highlighted by the authors, their model suffers from the lack of experimental data for validation, with only one study available about volatile species emission during torrefaction [6]. Moreover, although it has been shown that both solid yield and volatile species yields were highly influenced by the biomass type [6-8], the torrefaction models mentioned above generally do not describe the influence of biomass type. As most pyrolysis models,they consider biomass as a global solid and are thus feedstockspecific. Only Rousset et al. [2] have developed a model which could be applied to various biomasses. Their approach was based on an approach previously developed in pyrolysis by Koufopanos et al. [9]. This approach consists in considering the summative contribution of the biomass macromolecular constituents, which are known to react differently under the effect of heat [10]. Unfortunately, this model was limited to the description of solid mass loss versus time. Moreover, the model physical meaning was disputable, since its parameters were not derived from experiments on constituents. 


\begin{tabular}{|c|c|c|c|}
\hline \multicolumn{2}{|c|}{ Nomenclature } & & volatile species produced by step $1,-$ \\
\hline A & initial solid, - & $\mathrm{V}_{x}$ & complementary species, - \\
\hline$A_{1}$ & intermediate solid produced by reaction $1,-$ & $Y_{\mathrm{A}}$ & Yield of remaining initial solid, wmf\% \\
\hline$A_{2}$ & torrefied solid produced by reaction $2,-$ & $Y_{\mathrm{A} 1}$ or $\mathrm{A} 2$ & yield of solid produced by step 1 or step 2, wmf\% \\
\hline$c_{\mathrm{s}}$ & variation of mass percent of constituent s, wmf\% & $Y_{\mathrm{S}}$ & total yield of solid, wmf\% \\
\hline Ea & activation energy, J.mol ${ }^{-1}$ & $Y_{\mathrm{V}}$ & total yield of volatiles, wmf\% \\
\hline$F$ & $\begin{array}{l}\text { function describing the difference between model and } \\
\text { experimental yields, wmf\% }\end{array}$ & $\begin{array}{l}Y_{\mathrm{V} 1} \text { or } \mathrm{V} 2 \\
Y_{\text {sum } i}\end{array}$ & $\begin{array}{l}\text { yield of volatiles produced by step } 1 \text { or step } 2 \text {, wmf } \% \\
\text { total yield of species } i \text {, wmf } \%\end{array}$ \\
\hline$k$ & kinetic parameter, $\mathrm{s}^{-1}$ & $\alpha_{i \mathrm{~V} 1}$ or $\mathrm{V} 2$ & parameter describing the production of species $i$ in \\
\hline$k_{0}$ & preexponential factor, $\mathrm{s}^{-1}$ & & step 1 or $2,-$ \\
\hline$K_{1}$ or 2 & sum of kinetic parameters associated to step 1 or $2, s^{-1}$ & $\omega_{j}$ & initial mass fraction of constituent $j, w m f \%$ \\
\hline$R$ & universal gas constant, $\mathrm{J} \cdot \mathrm{mol}^{-1} \cdot \mathrm{K}^{-1}$ & $\mathrm{w} \%$ & mass percent \\
\hline$T$ & temperature, $\mathrm{K}$ & $\mathrm{wmf} \%$ & moisture-free mass percent \\
\hline$t_{\mathrm{N}}$ & interaction factor, - & & \\
\hline
\end{tabular}

In part 1 of this paper, an original set of experimental data was supplied about solid mass loss and volatiles production during torrefaction of beechwood, of its macromolecular constituents, i.e. cellulose, xylan and lignin, and of their mixtures. These data showed the ability of the additive law applied on constituents to describe torrefaction up to $250^{\circ} \mathrm{C}$ and the existence of interactions between constituents at temperatures of $280^{\circ} \mathrm{C}$ and $300^{\circ} \mathrm{C}$, maybe due to the ramification of cellulose fragments by lignin and xylan radicals produced at the beginning of torrefaction.

Based on the existing work in literature and on part 1 of this paper, the objective of part 2 is to derive from the experimental results a simple model able to predict both solid yield and the main volatile species yields during torrefaction versus temperature, residence time and biomass macromolecular composition through the use of a corrected additive law on biomass constituents.

First, the model principle will be described. The parameters determination will then be detailed. To end, the model performances will be discussed as well as the influence of biomass macromolecular composition on the results.

\section{Model development}

\subsection{Preambue}

The model assumptions rely on the large set of experimental results obtained in part 1 . The model has therefore some physical basis and it may also be a useful tool to better understand the torrefaction processes. However, it does not claim to be an extensive phenomenological description of biomass torrefaction. Indeed, this semi-empirical model mainly aims at being a simple tool that may be integrated in reactor models for further process design.

\subsection{Model description}

The general principle of the model is described in the scheme of Fig. 1. The input data are the contents in biomass constituents, i.e. cellulose, lignin and hemicelluloses. Hemicelluloses are represented by two constituents: xylan and acetyl groups. This choice enables to describe the production of acetic acid by the hydrolysis

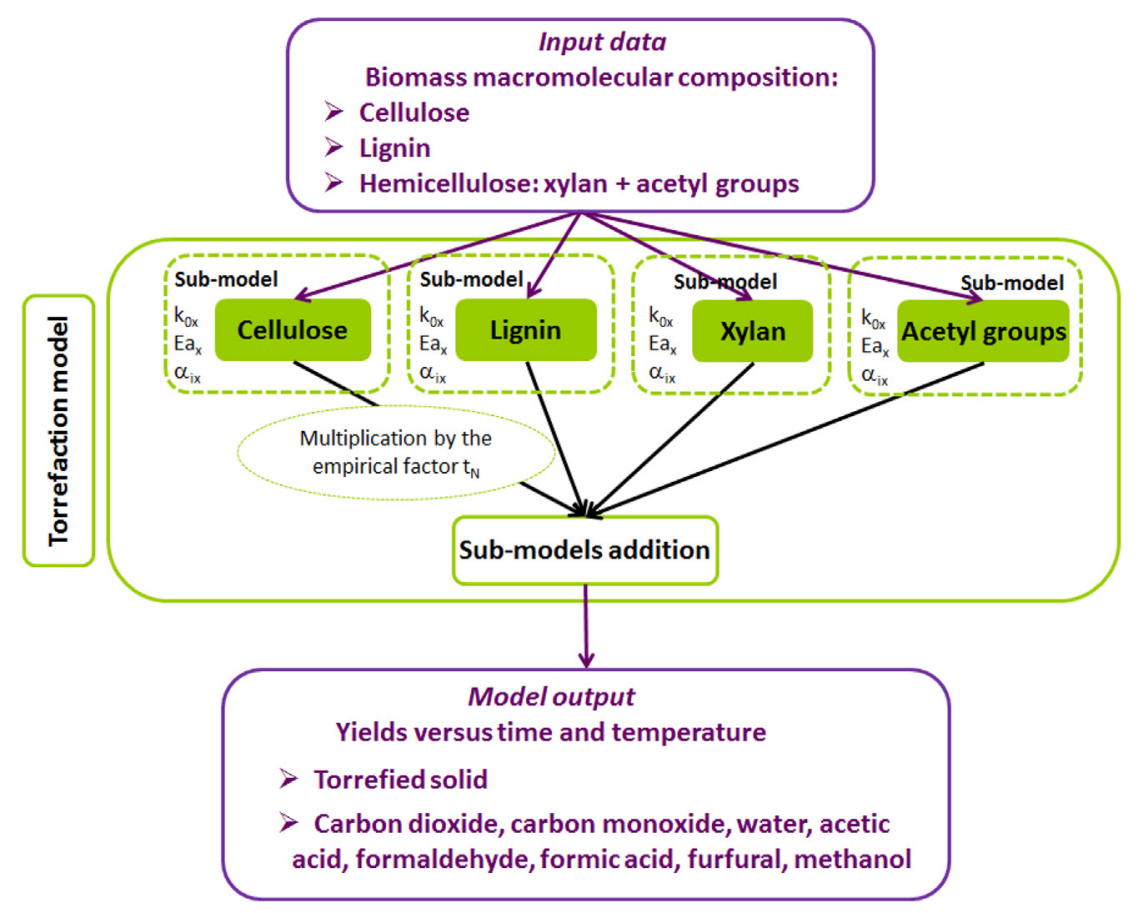

Fig. 1. Principle of the model. 
Table 1

Kinetic parameters value for the different constituents.

\begin{tabular}{llcc}
\hline Constituent & Kinetic parameter & $k_{0}\left(\mathrm{~s}^{-1}\right)$ & $\mathrm{Ea}\left(\mathrm{kJ} \cdot \mathrm{mol}^{-1}\right)$ \\
\hline Cellulose & $k_{\mathrm{A} 1}$ & $1.32 \times 10^{12}$ & 171 \\
& $k_{\mathrm{V} 1}$ & $1.06 \times 10^{21}$ & 268 \\
& $k_{\mathrm{A} 2}$ & $2.10 \times 10^{33}$ & 392 \\
& $k_{\mathrm{V} 2}$ & $3.09 \times 10^{18}$ & 230 \\
Lignin & $k_{\mathrm{A} 1}$ & $2.33 \times 10^{3}$ & 92 \\
& $k_{\mathrm{V} 1}$ & $1.36 \times 10^{5}$ & 88 \\
& $k_{\mathrm{A} 2}$ & 1.03 & 38 \\
& $k_{\mathrm{V} 2}$ & $3.41 \times 10^{4}$ & 93 \\
Xylan & $k_{\mathrm{A} 1}$ & $1.18 \times 10^{7}$ & 96 \\
& $k_{\mathrm{V} 1}$ & $1.67 \times 10^{10}$ & 133 \\
& $k_{\mathrm{A} 2}$ & $7.21 \times 10^{8}$ & 127 \\
& $k_{\mathrm{V} 2}$ & $2.50 \times 10^{9}$ & 136 \\
& $k_{\mathrm{A} 1}$ & $1.61 \times 10^{2}$ & 59 \\
& $k_{\mathrm{V} 1}$ & $6.46 \times 10^{6}$ & 110 \\
& $k_{\mathrm{A} 2}$ & $5.32 \times 10^{-2}$ & 9 \\
& $k_{\mathrm{V} 2}$ & $4.22 \times 10^{12}$ & 149 \\
\hline
\end{tabular}

of acetyl groups, which are absent from the extracted xylan, as explained in part 1 . Besides, as explained also in part 1, ash and extractives are not taken into account.

For each constituent, a kinetic sub-model was developed. As most existing torrefaction models, each sub-model was based on the semi-global mechanism proposed by Di Blasi and Lanzetta [11]. It enables to describe the two-phase process observed in the evolution of mass loss versus time during torrefaction. Indeed, this mechanism consists in a series of two sequential reactions, as shown in Equation (1). First, two parallel reactions occur. One gives rise to volatile species called $V_{1}$, the other one gives rise to an intermediate solid $A_{1}$. This intermediate solid is then assumed to react, as previously, through two parallel reactions. One gives rise to volatile species named $V_{2}$ and the other one to the torrefied solid $A_{2}$. Each reaction $x$ was assumed to obey a first order kinetics and the associated kinetic parameters $k_{x}$ were assumed to follow the Arrhenius law (see Equation (2)).

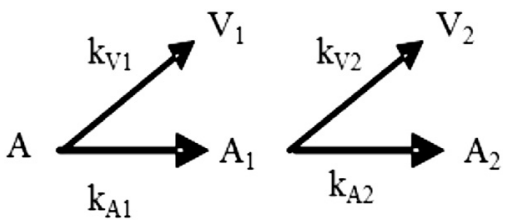

$k_{x}=k_{0 x} \exp \left(\frac{-\mathrm{Ea}_{x}}{R T}\right)$

where $k_{0 x}$ is the preexponential factor, $\mathrm{Ea}_{x}$ the activation energy, $R$ the universal gas constant and $T$ the temperature.

Based on this mechanism, the solid mass $Y_{S}$ is equal at each moment to the sum of the $A, A_{1}$ and $A_{2}$ masses $Y_{\mathrm{A}}, Y_{\mathrm{A} 1}$ and $Y_{\mathrm{A} 2}$ (Equation (3)) and the total volatile yield is $Y_{\mathrm{V}}$ equal to the sum of $V_{1}$ and $V_{2}$ yields $Y_{\mathrm{V} 1}$ and $Y_{\mathrm{V} 2}$ (Equation (4)).

$Y_{\mathrm{S}}=Y_{\mathrm{A}}+Y_{\mathrm{A} 1}+Y_{\mathrm{A} 2}$

$Y_{\mathrm{V}}=Y_{\mathrm{V} 1}+Y_{\mathrm{V} 2}$

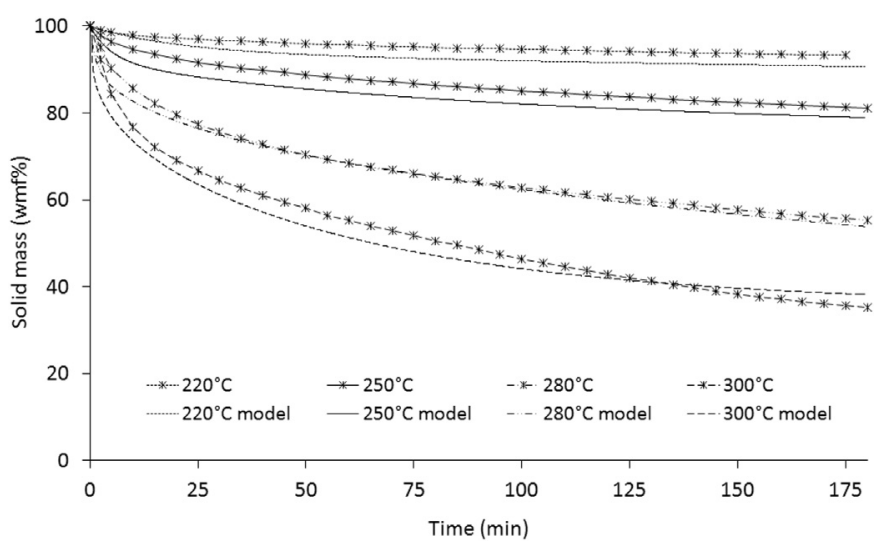

Fig. 2. Comparison between experimental solid mass loss and model prediction at the four temperatures tested.

As reactions are assumed to obey first-order kinetics, the yields in solid $Y_{\mathrm{S}}$ and in volatiles $Y_{\mathrm{V} 1}$ and $Y_{\mathrm{V} 2}$ are given by Equations (5)-(7). The obtention of these equations is not mentioned here as it can be found in the papers of Di Blasi and Lanzetta [11] and of Prins et al. [12].

$$
\begin{aligned}
Y_{\mathrm{S}}= & \left(1+\left(\frac{k_{\mathrm{A} 1} K_{1}-k_{\mathrm{A} 1} k_{\mathrm{A} 2}}{K_{1}\left(K_{2}-K_{1}\right)}\right)\right) \exp \left(-K_{1} t\right) \\
& +\left(\frac{-k_{\mathrm{A} 1} K_{2}+k_{\mathrm{A} 1} k_{\mathrm{A} 2}}{K_{2}\left(K_{2}-K_{1}\right)}\right) \exp \left(-K_{2} t\right)+\frac{k_{\mathrm{A} 1} k_{\mathrm{A} 2}}{K_{1} K_{2}} \\
Y_{\mathrm{V} 1}= & \frac{k_{\mathrm{V} 1}}{K_{1}}\left(1-\exp \left(-K_{1} t\right)\right) \\
Y_{\mathrm{V} 2}= & \frac{k_{\mathrm{V} 2} k_{\mathrm{A} 1}}{K_{1} K_{2}\left(K_{1}-K_{2}\right)}\left(K_{1}-K_{2}-K_{1} \exp \left(-K_{2} t\right)+K_{2} \exp \left(-K_{1} t\right)\right)
\end{aligned}
$$

with:

$$
\begin{aligned}
& K_{1}=k_{\mathrm{A} 1}+k_{\mathrm{V} 1} \\
& K_{2}=k_{\mathrm{A} 2}+k_{\mathrm{V} 2}
\end{aligned}
$$

Volatile species from the two reactions were assumed to be composed of the eight main species produced during torrefaction experiments: carbon dioxide, carbon monoxide, water, formaldehyde, acetic acid, furfural, methanol and formic acid. To describe the volatiles composition, a parameter $\alpha_{i x}$ was associated to each species $i$ for each reaction. The yield of the species was then given by Equation (3).

$Y_{\mathrm{sum} i}=\alpha_{i \mathrm{~V}_{1}} Y_{\mathrm{V}_{1}}+\alpha_{i \mathrm{~V}_{2}} Y_{\mathrm{V}_{2}}$

\begin{tabular}{|c|c|c|c|c|c|c|c|c|}
\hline Constituent & Carbon dioxide & Carbon monoxide & Water & Formaldehyde & Furfural & Formic acid & Methanol & $V_{x}$ \\
\hline Cellulose & 0.028 & 0.008 & 0.426 & 0.120 & 0.001 & - & - & 0.417 \\
\hline Lignin & 0.045 & 0.020 & 0.350 & 0.470 & 0.004 & - & 0.027 & 0.084 \\
\hline Xylan & 0.233 & 0.077 & 0.430 & 0.025 & - & 0.023 & 0.042 & 0.170 \\
\hline
\end{tabular}

where $Y_{\mathrm{sum} i}, Y_{\mathrm{V} 1}$ and $Y_{\mathrm{V} 2}$ are the global yield of species $i$, the yield of volatiles by reaction 1 and the yield of volatiles by reaction 2 respectively and with

Table 2

Value of the coefficients associated to the production of volatile species for each constituent. 
Table 3

Comparison between experimental and model yields at $220,250,280$ and $300{ }^{\circ} \mathrm{C}$ for the main volatile species.

\begin{tabular}{|c|c|c|c|c|c|c|c|c|c|}
\hline Temperature $\left({ }^{\circ} \mathrm{C}\right)$ & Yield (wmf\%) & Carbon dioxide & Carbon monoxide & Water & Formaldehyde & Furfural & Formic acid & Acetic acid & Methanol \\
\hline \multirow[t]{3}{*}{220} & Experimental & 1.48 & 0.50 & 3.42 & 1.35 & 0.01 & 0.13 & 0.90 & 0.31 \\
\hline & Model & 0.67 & 0.10 & 2.22 & 1.59 & 0.00 & 0.00 & 0.95 & 0.47 \\
\hline & Absolute error & 0.81 & 0.40 & 1.20 & 0.24 & 0.01 & 0.13 & 0.05 & 0.15 \\
\hline \multirow[t]{3}{*}{250} & Experimental & 2.93 & 0.99 & 7.29 & 2.58 & 0.02 & 0.26 & 3.37 & 0.60 \\
\hline & Model & 2.43 & 0.38 & 6.21 & 3.46 & 0.05 & 0.77 & 3.18 & 0.77 \\
\hline & Absolute error & 0.51 & 0.61 & 1.09 & 0.88 & 0.04 & 0.51 & 0.19 & 0.17 \\
\hline \multirow[t]{3}{*}{280} & Experimental & 4.20 & 1.40 & 16.97 & 5.97 & 0.05 & 0.33 & 5.45 & 0.79 \\
\hline & Model & 3.43 & 1.11 & 12.45 & 5.84 & 0.17 & 1.53 & 5.32 & 1.09 \\
\hline & Absolute error & 0.77 & 0.29 & 4.52 & 0.13 & 0.13 & 1.20 & 0.13 & 0.30 \\
\hline \multirow[t]{3}{*}{300} & Experimental & 4.93 & 1.64 & 23.24 & 8.31 & 0.07 & 0.36 & 5.90 & 0.90 \\
\hline & Model & 4.72 & 1.82 & 21.01 & 8.15 & 0.33 & 2.04 & 6.14 & 1.50 \\
\hline & Absolute error & 0.21 & 0.19 & 2.23 & 0.16 & 0.27 & 1.68 & 0.25 & 0.60 \\
\hline
\end{tabular}

$\sum_{i} \alpha_{i \mathrm{~V}_{1}}=\sum_{i} \alpha_{i \mathrm{~V}_{2}}=1$

As the composition of volatiles was found to be roughly the same under the range of temperatures investigated during experiments, these parameters were assumed to be constant whatever the temperature. Besides, as a first approximation, the volatiles composition was assumed to be constant over time and the parameters $\alpha_{i \mathrm{~V} 1}$ and $\alpha_{i \mathrm{~V} 2}$ were thus assumed to be equal. Since it was observed that each constituent did not produce all species, some constants were taken equal to zero:

- Cellulose only gives rise to carbon dioxide, carbon monoxide, water, formaldehyde, furfural;

- Lignin only produces carbon dioxide, carbon monoxide, water, formaldehyde, furfural, methanol;

- Xylan only produces carbon dioxide, carbon monoxide, water, formaldehyde, methanol, formic acid;

- As explained above, acetyl groups produce acetic acid.

As all volatile species were not measured in experiments, a complementary species $V_{x}$ was added to close the mass balance.

To obtain the biomass torrefaction model, the additive law was applied by summing the contribution of each constituent submodel. As discussed in part 1 of this paper, interactions could be observed between cellulose and the two other constituents at $280{ }^{\circ} \mathrm{C}$ and $300{ }^{\circ} \mathrm{C}$, maybe due to the ramification of cellulose fragments by lignin and xylan radicals produced at the beginning of torrefaction. To describe these interactions, a corrective interaction factor $t_{\mathrm{N}}$ was added to the kinetic parameters $k_{\mathrm{A} 1}, k_{\mathrm{A} 2}, k_{\mathrm{V} 1}$ and $k_{\mathrm{V} 2}$ in cellulose sub-model.

\subsection{Parameters determination}

To determine the values of model parameters, a function $F$ was defined. This function $F$ characterizes the difference between experimental yield and predicted yield (see Equation (12)). $F$ was minimized for the four temperatures investigated during the isothermal period of the experiments.

$F=\sum_{t}\left|Y_{i \text { model }}-Y_{i \exp }\right|$

\subsubsection{Sub-models parameters}

To determine for each sub-model the kinetic parameters, i.e. the preexponential factor $k_{0 x}$ and the activation energy $\mathrm{Ea}_{x}$, the function $F$ was defined as the absolute value of the difference between solid yield versus time obtained in the thermogravimetric experiments (see part 1 of this paper) and solid yield calculated from Equation (5).
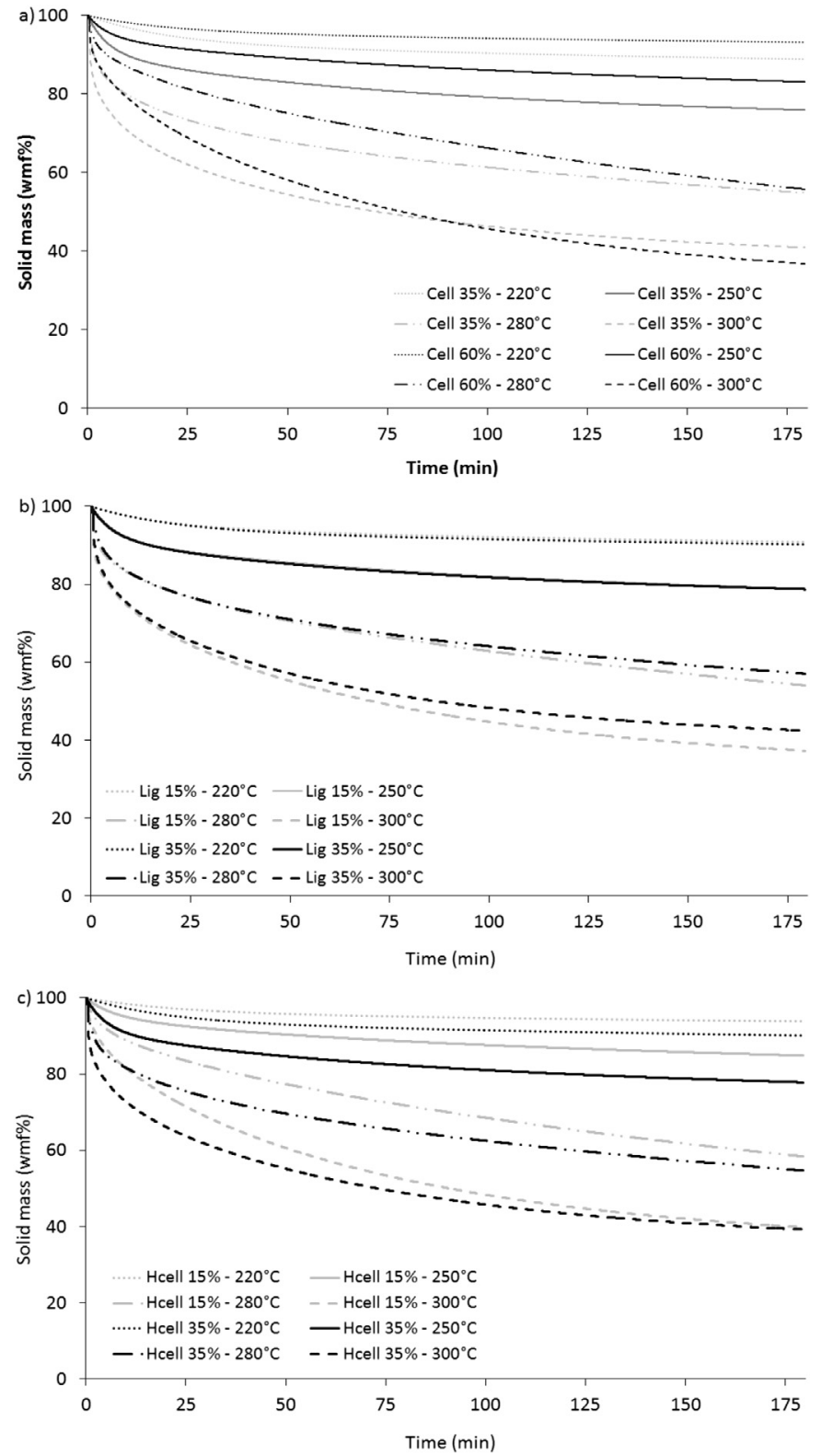

Fig. 3. Model predictions of solid mass loss versus time at $220^{\circ} \mathrm{C}, 250{ }^{\circ} \mathrm{C}, 280^{\circ} \mathrm{C}$ and $300{ }^{\circ} \mathrm{C}$ for different contents in a) cellulose; b) lignin and c) hemicelluloses. 

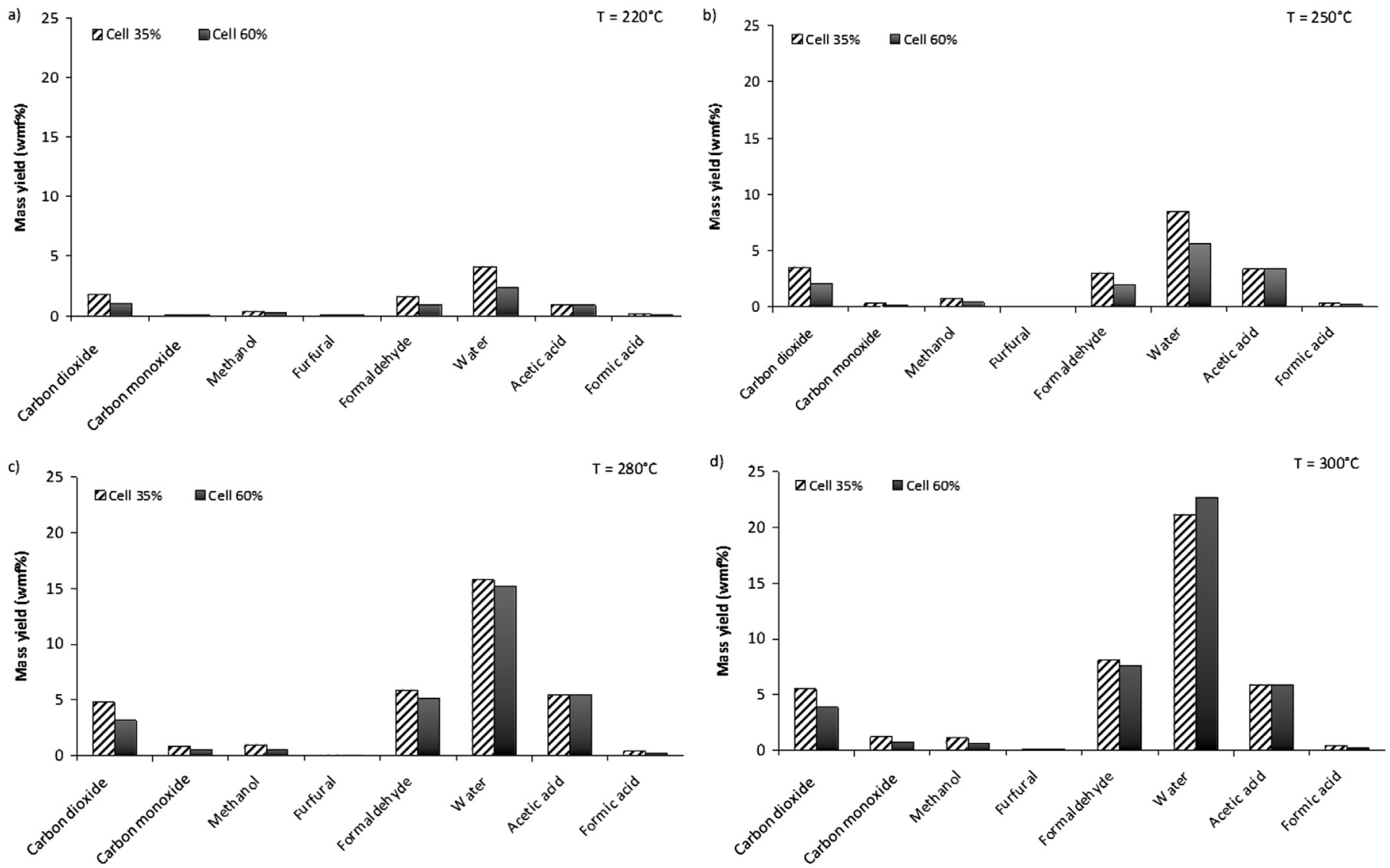

Fig. 4. Model predictions of volatile species yields for different contents in cellulose after $3 \mathrm{~h}$ of torrefaction at a) $220^{\circ} \mathrm{C}$; b) $250{ }^{\circ} \mathrm{C}$; c) $280{ }^{\circ} \mathrm{C}$; d) $300{ }^{\circ} \mathrm{C}$.

To determine for each sub-model the parameters $\alpha_{i s}$ describing volatiles composition, $F$ was defined as the absolute value of the difference between total yield of volatile species $i$ obtained in experiments in TORNADE (see part 1 of this paper) and that calculated from Equations (6), (7) and (10).

The values obtained are given in Table 1 for the kinetic parameters and in Table 2 for the constants describing volatiles composition.

It appears hazardous to make a direct comparison between the kinetic parameters found in this study and the kinetic parameters of pyrolysis models. Indeed, as explained in introduction, these models are valid in a range of temperature different from those of torrefaction and may therefore describe other phenomena. Similarly, it seems difficult to compare kinetic parameters associated to different mechanisms, i.e. one-step or two-step. However, a comparison could be made with the kinetic parameters found by Repellin et al. on hemicelluloses with the same two-step mechanism at the same temperature level [4]. The activation energies found by Repellin et al. were $30-80 \mathrm{~kJ} \mathrm{~mol}^{-1}$ lower than the present ones and surprisingly the preexponential factor he found for the second reaction of volatiles production was equal to zero. Such differences must be due to the compensation effect occurring in the kinetic parameters determination: different couples of preexponential factor and energy activation may fulfill the numerical criteria.

\subsubsection{Factor describing the interactions between constituents}

To determine the interaction factor $t_{\mathrm{N}}, F$ was defined as the absolute difference between solid yield versus time measured during mixtures tests and solid yield predicted based on the behavior of constituents alone.
The value was found to be nearly the same when obtained from tests on cellulose-xylan or on cellulose-lignin. This shows that the interactions have the same effect on the mixture mass loss evolution.

This value varied with temperature: it was of 1 at $250{ }^{\circ} \mathrm{C}$, of 0.54 at $280{ }^{\circ} \mathrm{C}$ and of 0.32 at $300{ }^{\circ} \mathrm{C}$. This means that the interactions effect tends to become stronger with temperature with a more significant decrease in cellulose decomposition rate, that is, approximately of a factor 2 at $280{ }^{\circ} \mathrm{C}$ and of a factor 3 at $300{ }^{\circ} \mathrm{C}$.

\section{Results}

\subsection{Model performances}

As shown in Fig. 2, the model was able to predict with satisfactory accuracy the solid mass loss versus time within the range of temperatures tested. Indeed, the absolute difference between experiments and model was always below $3 \%$.

The experimental and model yields are compared for the main volatile species in Table 3 . The differences between experiments and model were relatively similar for all temperatures but varied according to species: the relative difference was of $35 \%$ or less for carbon dioxide, water, formaldehyde, acetic acid and methanol. It was slightly higher (50\%) for carbon monoxide. Hence, for all these species, the prediction could be considered as quite good as it enables to get a correct estimation of the amount of products. The results were not so satisfactory for two minor species: formic acid, with a difference of $200 \%$ and furfural, with a difference of $300 \%$. However, such high difference may be explained by the very low amounts of these species in the experiments. 

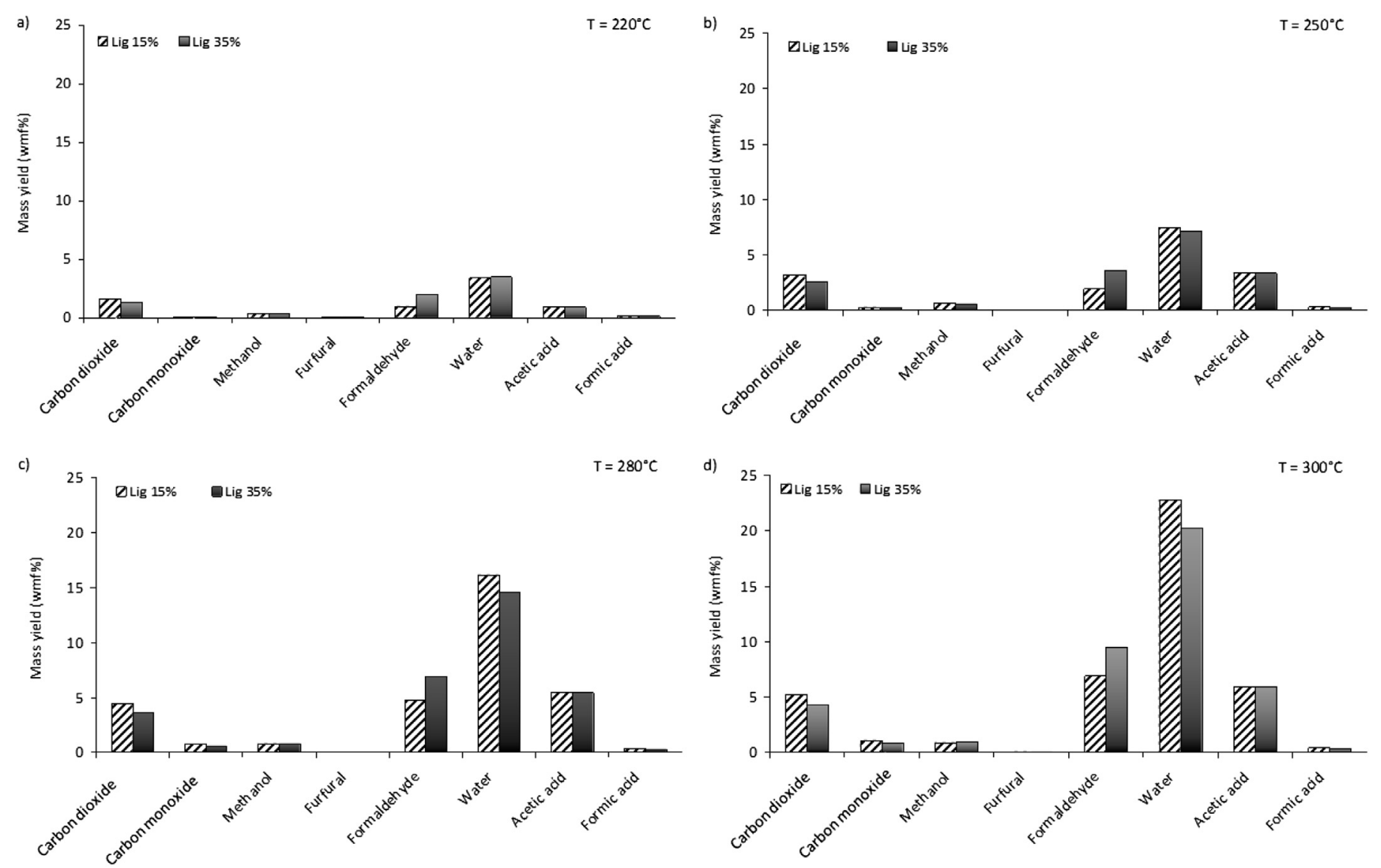

Fig. 5. Model predictions of volatile species yields for different contents in lignin after $3 \mathrm{~h}$ of torrefaction at a) $220{ }^{\circ} \mathrm{C}$; b) $250{ }^{\circ} \mathrm{C}$; c) $280{ }^{\circ} \mathrm{C}$; d) $300{ }^{\circ} \mathrm{C}$.
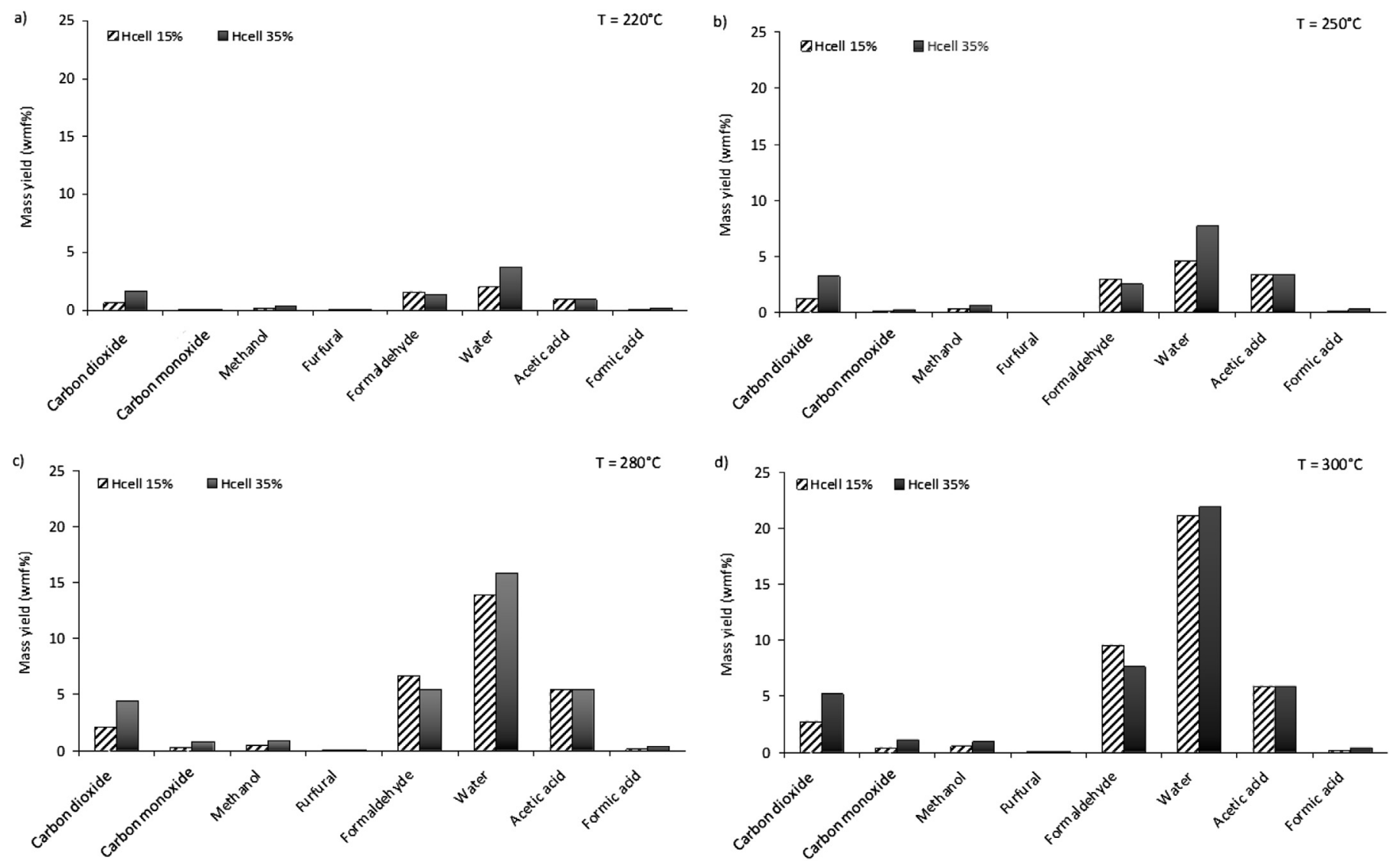

Fig. 6. Model predictions of volatile species yields for different contents in hemicelluloses after $3 \mathrm{~h}$ of torrefaction at a) $220{ }^{\circ} \mathrm{C}$; b) $250{ }^{\circ} \mathrm{C}$; c) $280{ }^{\circ} \mathrm{C}$; d) $300{ }^{\circ} \mathrm{C}$. 


\subsection{Influence of the initial biomass composition}

Experiments have not been performed on other biomass samples with different macromolecular composition yet. The model was then used to investigate theoretically the influence of biomass macromolecular composition on the torrefaction process. Model calculations were performed by varying the amounts of cellulose, hemicelluloses and lignin in the initial biomass. The values were chosen in the limit of the range typically encountered in literature about biomass [13]:

- Cellulose from 35 to $60 \mathrm{w} \%$

- Lignin from 15 to $35 \mathrm{w} \%$

- Hemicelluloses from 15 to $35 \mathrm{w} \%$.

Note that these three parameters are not independent. It was chosen to compensate the variation of a constituent by the variation of the two other ones, the ratio between them remaining unchanged. Hence a decrease of the constituent 1 of $x$ $\mathrm{w} \%$ resulted in an increase of the constituents 2 and 3 of $c_{2} x$ w\% and $c_{3} x$ w\% respectively, with $c_{2}$ and $c_{3}$ given by Equations (13) and (14).

$c_{2}=\frac{\omega_{2}}{\omega_{2}+\omega_{3}}$

$c_{3}=\frac{\omega_{3}}{\omega_{2}+\omega_{3}}$

where $\omega_{j}$ is the initial mass fraction of the constituent $j$ in biomass. As illustrated in Figs. 3-6, the main results were:

- An increase of lignin content has no effect on solid yield; it mainly leads to an increase of formaldehyde yield.

- An increase of hemicelluloses content impacts the mass loss that becomes higher. This increase is logically visible at the beginning of torrefaction, when most hemicelluloses are degraded. This gives rise to an increase of carbon dioxide, carbon monoxide and water.

- A higher cellulose amount leads to a decrease of solid mass loss and volatiles yield at $220^{\circ} \mathrm{C}$ and $250{ }^{\circ} \mathrm{C}$, which is logical since this constituent is not attacked at these temperatures.

- The mass loss of solid with the highest cellulose amount is higher at $280{ }^{\circ} \mathrm{C}$ and $300{ }^{\circ} \mathrm{C}$ after $60 \mathrm{~min}$ of torrefaction than the mass loss of solid with the smallest amount. This is related to a higher production of water when cellulose content increases.

\section{Conclusion}

Based on the experimental results obtained in part 1 of this twopaper series, a semi-empirical model was developed. This model is the first literature attempt to predict both solid and the main volatile species yields (carbon dioxide, carbon monoxide, water, formaldehyde, acetic acid, furfural, methanol and formic acid) produced during biomass torrefaction versus temperature, residence time and biomass macromolecular constituents. The addition of kinetic sub-models developed for each constituent cellulose, lignin, xylan and acetyl groups - gave satisfactory results provided a corrective factor was added on cellulose decomposition rate at temperatures above $280^{\circ} \mathrm{C}$. This corrective factor took into account the interactions between cellulose and the two other main constituents. In the future, this model may be integrated in reactor model.

\section{References}

[1] Van der Stelt MJC, Gerhauser H, Kiel JHA, Ptasinski KJ. Biomass upgrading by torrefaction for the production of biofuels: a review. Biomass Bioenergy 2012;35:3748-62.

[2] Rousset P, Perre P, Turner I. Selection of a micro-particle wood pyrolysis model for use in a macroscopic transport model. Ann Sci 2005;63:1-17.

[3] Bates RB, Ghoniem AF. Biomass torrefaction: modeling of volatile and solid product evolution kinetics. Bioresour Technol 2012;124:460-9.

[4] Repellin V, Govin A, Rolland M, Guyonnet R. Modelling anhydrous weight loss of wood chips during torrefaction in a pilot kiln. Biomass Bioenergy 2010;34: 602-9.

[5] Di Blasi C. Modeling chemical and physical processes of wood and biomass pyrolysis. Prog Energy Combust Sci 2008;34:47-90.

[6] Prins MJ, Ptasinski KJ, Janssen FJJG. Torrefaction of wood: part 2. Analysis of products. J Anal Appl Pyrolysis 2006;77:35-40.

[7] Commandr'e JM, Rousset P, Lesueur G, Leboeuf A, Chafchaouni L.

Torrefdaitimass: influence of operating conditions on products. Waste Eng; 2010.

[8] Dupont C, Commandr'e JM, Pistolet L, Nocquet T, Verne-Tournon C, Da Silva Perez D, et al. Torrefaction behaviour of various biomass types: kinetics of solid mass loss and release of volatiles. TCBiomass 2011;2011.

[9] Koufopanos CA, Papayannakos N, Maschio G, Lucchesi A. Modeling the pyrolysis of biomass particles: studies on kinetics, thermal and heat transfer effects. Can J Chem Eng 1991;69:907-15.

[10] Gaur S, Reed TB. Pyrolysis of the components of biomass. In: Ed. MD, editor Therm. Data Nat. Synth. Fuels; 1998. New York.

[11] Di Blasi C, Lanzetta M. Intrinsic kinetics of isothermal xylan degradation in inert atmosphere. J Anal Appl Pyrolysis 1997;40-41:287-303.

[12] Prins MJ, Ptasinski KJ, Janssen FJJG. Torrefaction of wood: part 1. Weight loss kinetics. J Anal Appl Pyrolysis 2006;77:28-34.

[13] Vassilev SV, Baxter D, Andersen LK, Vassileva CG. An overview of the chemical composition of biomass. Fuel n.d;89:913-933. 